\title{
Acoustic Emission Evaluation of Fatigue Life Prediction for a Carbon Steel Specimen using a Statistical-Based Approach.
}

\begin{abstract}
This study was carried out to investigate the relationship between the strain and acoustic emission (AE) signals to ascertain the applicability of $\mathrm{AE}$ in predicting the fatigue life of metallic specimens. This paper is an extension research of previous work that has been published before. Previous paper presents the ability of AE to predict the fatigue life using statistical parameters such as root mean square (r.m.s) and kurtosis. The same approach also has been carried out in this recent paper but this time, the common parameters that can be directly extracted from the $\mathrm{AE}$ data acquisition system were used. To achieve the objective, the strain and $\mathrm{AE}$ signals were measured using a strain gauge and a $\mathrm{AE}$ piezoelectric transducer on SAE 1045 steel specimens. These measurements were conducted during the cyclic test at constant loadings of $570 \mathrm{MPa}, 610 \mathrm{MPa}$, and $650 \mathrm{MPa}$. For data collection, AE parameters, i. e., count rate, hits, and duration, were extracted from specific software and were then correlated to fatigue lives calculated using the strain data. Fatigue life values were calculated using strain-life models. The correlation between the experimental and predicted values of fatigue life was then established by the so-called coefficient of correlation which is within $97.2 \%$ and $98.5 \%$ for the Coffin-Manson model and between $92.7 \%$ and $94.3 \%$ for the Smith-Watson-Topper model, respectively. As for the Morrow model, the coefficient of correlation was tabulated at approximately between $71.9 \%$ and $73.6 \%$. Good correlation values expressed that the $\mathrm{AE}$ technique is applicable for predicting the fatigue life of metallic specimens.
\end{abstract}

Keyword: Acoustic Emission 